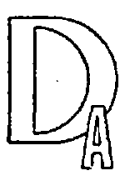

\title{
DOCUMENTACION ADMINISTRATIUA
}

Secretaría General Téonica de la Presidencia del Gobierno

Madrid, febrero 1960

Nimero 26

Depósito legæl: M. 581 - 1958

S U M A R I O

Pégı́nas

1 EDITORI

- La selección para el ingreso en la Aaministración Pública.

(I) El sistema de oposición, por Miguel Siguán Soler ...... 7

- Notas sobre función y técnica de los organigramas. Una aplicación en el ambito local, por. Luis Blanco de Tella ......... 23

E Principios básicos de la dirección de personal en la Adminis-

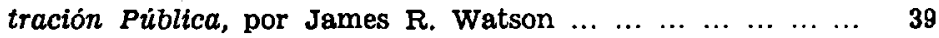

- Ambientación de oficinas, por José Maria Casals Marcén ... ... 48

3 cronICAS $Y$ NOTICIAS:

1. Crónicas :

- Un sistema de incentivos en favor del personal del Ins-

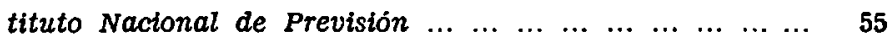

- La oficina para la reforma de la Administración en Italia. $\quad 60$

- Resumen legislativo del mes de enero de $1960 \ldots \ldots \ldots$

2. La ADMinistración española vista desde ei eXtranjero $\ldots \ldots \ldots$

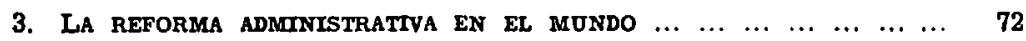

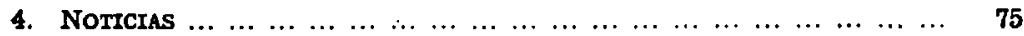


(4) COMUNICACIONES E INICIATIVAS:

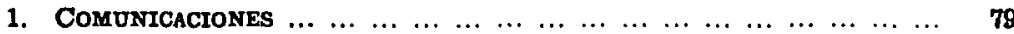

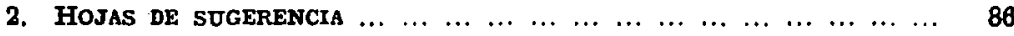

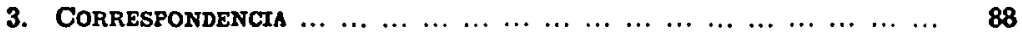

\section{DOCUMENTACION BIBLIOGRAFICA :}

1. Bibliografia :

- Organización del Trabajo Administrativo, por Luis Enrique

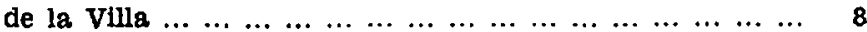

2. NOTAS INFORMATIVAS :

- Cursos de Psicologia y Soctología aplicadas a la Administración del Instituto Técnico de las Administraciones pi-

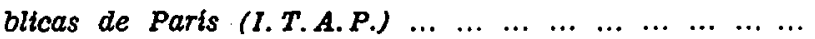

- El egograma: un medio para comprobar el empleo del per-

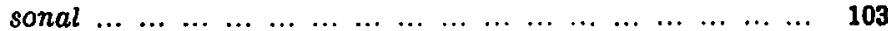

- La racionalizactón del trabajo administrativo en la Caja de Ahorros $y$ de Retiros de Bélgica $\ldots \ldots \ldots \ldots \ldots \ldots$

- La conducta del subordinado ante las brdenes ... ... ... . . 110

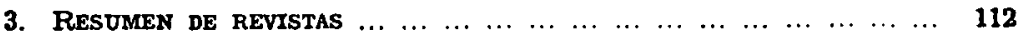

\section{APENDICES:}

Fichas del contenido de Docdmentación admenistratrva num. 26. Hoja de Sugerencia.

DOCUMENTACTóN ADMINISTRATIVA NO SE IDENTIFICA NECESARIAMENTE CON LAS OPTNIONES O JUCIOS QUE LOS AUTORES EXPONGAN EN USO DE LA LIBERTAD INTELECTUAL QUE SE LES BRINDA 